\title{
O USO DE DISPOSITIVOS MÓVEIS NO ENSINO/APRENDIZAGEM DE LÍNGUA INGLESA
}

\author{
Sandra Sayuri Silva Shibasaki* \\ Diógenes Cândido de Lima**
}

RESUMO: O acesso a cultura digital e aos novos recursos de comunicação, pode proporcionar aos docentes e profissionais da educação uma maneira de ampliar os espaços não formais de aprendizagem. Somos a sociedade da interação e da hipermobilidade, resultado da cultura digital e do uso da tecnologia. Para trazer esses conceitos para a realidade da educação, devemos pensar práticas pedagógicas que promovam o acesso de nossos alunos à cibercultura, onde eles possam produzir conhecimento de maneira colaborativa e, principalmente, se sintam incluídos nessa nova comunidade mundial. Como referencial teórico, utilizamos Kumaravadivelu (2016), Santaella (2010 e 2013), Castels (1999), Bohn (2014), Moran (2017), Leffa (2013), Prensky(2017), Paiva (2001, 2017), Xavier (2017), entre outros. O presente trabalho tem como finalidade discutir como os professores podem se apropriar das tecnologias para assegurar o aprendizado de língua inglesa, bem como a utilização dos dispositivos móveis na educação, enfocando o ensino/aprendizagem de língua inglesa.

PALAVRAS-CHAVE: Uso de tecnologia na aprendizagem; Aprendizagem ubíqua; Língua inglesa; M-learning

\footnotetext{
* Mestranda do Programa de Pós-Graduação em Letras: Cultura, Educação e Linguagens, pela Universidade Estadual do Sudoeste da Bahia (Uesb).

** Professor Pleno da Universidade Estadual do Sudoeste da Bahia (Uesb). Doutorado em Educação pela Southern Illinois University at Carbondale, Estados Unidos.
} 


\section{Considerações iniciais}

Use their tools! Speak their language! If we are smart, the mobile phones and games that our students are so comfortable with will soon become their learning tools. ${ }^{1}$

(Marc Prensky)

A sociedade contemporânea se caracteriza por ser uma era de constantes e rápidas mudanças, sobretudo em relação às novas tecnologias e, consequentemente, às novas formas de linguagens, impactadas também pela globalização. Diante dessas mudanças ocasionadas pelo uso das tecnologias, apresentamos uma discussão com novas possibilidades pedagógicas que podem ser incorporadas à educação, de maneira a auxiliar o trabalho docente através de novos métodos de ensino, como também acesso e compartilhamento do conhecimento.

Os acontecimentos relacionados a vida social, cultural, econômica e tecnológica afetam a todos, numa velocidade nunca antes vista, fazendo também com que desapareçam as fronteiras nacionais em relação a essas novas ideias, culturas e valores que emergem. Nesse cenário, a língua inglesa surge como a língua da globalização. Então, tentar fazer com que nossos alunos tenham acesso a esse conhecimento e verdadeiramente aprendam a língua inglesa, para que se sintam parte desse novo mundo, é nosso maior desafio como professores.

O acesso à cultura digital e aos novos recursos de comunicação pode proporcionar aos docentes e profissionais da educação uma maneira de ampliar os espaços não formais de aprendizagem. Somos a sociedade da interação e da hipermobilidade, resultado da cultura digital e do uso da tecnologia. Para trazer esses conceitos para a realidade da educação, devemos pensar práticas pedagógicas que promovam o acesso de nossos alunos à

1 "Use as ferramentas deles! Fale sua linguagem! Se nós fomos espertos, os telefones móveis e jogos que nossos alunos tão confortavelmente usam em breve se transformarão nas ferramentas de aprendizagem deles." Tradução nossa. 
cibercultura, onde eles possam produzir conhecimento de maneira colaborativa e, principalmente, se sintam incluídos nessa nova comunidade mundial.

Como poderemos nos apropriar dessas tecnologias para assegurar o aprendizado dos nossos alunos? Este artigo tem como finalidade discutir a utilização dos dispositivos móveis na educação, enfocando o ensino/aprendizagem de língua inglesa. Como referencial teórico, utilizamos Kumaravadivelu (2016), Santaella (2010 e 2013), Castels (1999), Bohn (2014), Moran (2017), Leffa (2013), Prensky(2017), Paiva ( 2001, 2017), Xavier (2017), entre outros.

Um dia a novidade foi a fita cassete. Depois vieram os laboratórios de línguas com aquelas cabines individuais e fones de ouvido, e então chegaram os livros didáticos com os esperados CD rooms, retroprojetores, TVs pen drive, computadores e agora vivemos a era dos dispositivos móveis. Antes deles os computadores só funcionavam atrelados a um emaranhado de fios. O sinal de internet só chegava conectando-se a um cabo. Hoje temos a liberdade de utilizar nossos pequenos computadores portáteis, conectá-los à internet através de dados móveis e sistemas wifi. É a era da conectividade. Em todos os ambientes sociais, inclusive a escola, o uso de smartphones, tablets, notebooks, tornou-se comum. A tecnologia mudou a organização e a forma de comunicação da sociedade contemporânea e, por conseguinte, o acesso ao conhecimento. As tecnologias nos conectam a um mundo novo, cheio de possibilidades, onde os sujeitos que emergem nesse novo modelo de sociedade estão conectados através da grande rede mundial. Sendo assim, as tecnologias não podem e nem devem ser vistas apenas como simples instrumentos de comunicação, mas como um poderoso instrumento que deve ser utilizado de maneira democrática, mas sobretudo consciente, em face do seu poder sócio-político.

Costumamos relacionar o termo tecnologia a aparelhos rápidos, sofisticados e inteligentes, tais como o computador, tablet ou smartphone, mas não devemos nos esquecer de que o quadro-negro, o retroprojetor e o próprio livro, também são exemplos de tecnologia. Dessa forma, podemos pensar que todos esses aparatos podem estar a serviço da 
educação para nos ajudar a resolver problemas e nos auxiliar em nossa prática diária como professores.

O uso das tecnologias provoca mudanças, transforma a maneira como as pessoas se relacionam umas com as outras e interagem com o mundo. Esse cenário provoca expectativas nos professores e demais envolvidos no processo educacional e é por isso que devemos considerar quais são as crenças dos professores e alunos ao utilizarem as tecnologias no processo de ensino/aprendizagem. A tecnologia, em particular os dispositivos móveis, podem servir como ferramentas motivacionais no ensino de língua inglesa? Qual a relação entre o uso de tecnologia e o ensino de LI? E, por fim, qual ou quais são os principais desafios dos professores? Segundo Paiva (2001.p. 114),

Usar a internet no ensino de inglês é um desafio que demanda mudanças de atitude de alunos e professores. $\mathrm{O}$ aluno bem-sucedido não é mais aquele que armazena informações, mas aquele que se torna um bom usuário de informação. $\mathrm{O}$ bom professor não é mais o que tudo sabe, mas aquele que sabe promover ambientes que promovem a autonomia do aprendiz e que os desafia a aprender com o(s) outro(s) através de oportunidades de interação e de colaboração.

Segundo Kumaravadivelu (2016, p. 131), a internet é o traço mais distintivo da fase atual da globalização. O avanço da tecnologia e o consequente uso da internet como meio de comunicação global influenciam significativamente as identidades culturais e as comunidades linguísticas. Ele ainda acrescenta que,

Em um desenvolvimento sem precedentes na história humana, a internet tornou-se uma fonte singular que imediatamente conecta milhões de indivíduos com outros, com associações particulares e com instituições educacionais e agências governamentais, tornando as interações à distância e em tempo real possíveis.

Segundo uma pesquisa do United Nations Report on Human Development (1999:29, apud Kumaravadivelu 2016), a globalização tem modificado a paisagem mundial 
de maneira que as distâncias espacial e temporal estão diminuindo. A escola precisa propiciar o acesso dos seus alunos às tecnologias de informação e comunicação para que eles se sintam cidadãos do mundo que emerge. Fazer com que nossos alunos tenham acesso, conhecimento e verdadeiramente aprendam a língua inglesa e que se sintam parte desse novo mundo é nosso maior desafio como professores. Sobre o acesso ao conhecimento, Leffa (2009, p. 116) diz que,

o conhecimento está se tornando um valor cada vez mais precioso e, por isso, mais procurado. O problema, principalmente numa sociedade competitiva, é que não há interesse em distribuí-lo. Acredita-se que quanto menos pessoas detiverem determinado conhecimento, maior será seu valor para aqueles que o possuam.

Refletindo sobre o exposto, fico imaginando o caráter duplamente excludente que podemos ter enquanto professores de língua estrangeira. Se o advento da globalização ocasionou um rápido desenvolvimento nos meios de comunicação e nas tecnologias ao redor do mundo, e o idioma utilizado na maioria dos processos de comunicação é o inglês, estaria a escola hoje exercendo o seu papel em incluir nossos estudantes e prepará-los para enfrentar o mundo contemporâneo? Como poderemos nos apropriar dessas tecnologias para assegurar o aprendizado de uma língua estrangeira e assim fazer com nossos alunos se sintam parte da comunidade global?

Essas características do mundo moderno têm, por certo, implicações importantes para o processo educacional como um todo, e, particularmente, para o ensino de línguas na escola. Se essas megatendências forem descrições exatas do panorama futuro, é importante que se considere como preparar os jovens para responderem às exigências do novo mundo. (PCN, Língua Estrangeira, p. 38)

Os jovens de hoje têm ao seu alcance vários dispositivos móveis, a exemplo de smartphones, tablets, notebooks, iPads , mp3 players. Uma geração que domina com total naturalidade o uso desses aparelhos. Atuo como professora de língua portuguesa e língua inglesa em uma escola da rede pública estadual da Bahia. Quem conhece a realidade das escolas públicas sabe que nem sempre temos acesso a matérias de apoio, então por que não 
utilizar o celular e os gadgets em auxílio da nossa prática pedagógica? Principalmente porque a maioria dos alunos e professores possuem ao menos um aparelho celular, muitos de última geração, e a tecnologia proporciona interatividade, acesso rápido a diferentes tipos de conhecimento, recursos como áudio, vídeo, imagens. O mundo na palma das mãos, literalmente. Segundo Santaella (2013), é a integração dos dispositivos móveis, na ubiquidade das redes, da informação, do conhecimento, da comunicação, das cidades e do pensamento. Somos a sociedade da interação e da hipermobilidade, resultado da cultura digital e do uso da tecnologia. $\mathrm{O}$ acesso a essa cultura digital e aos novos recursos de comunicação, pode proporcionar aos docentes e profissionais da educação uma maneira de ampliar os espaços não formais de aprendizagem. Santaella (2013) argumenta que a cultura digital está presente nos processos de aprendizagem aberta e ubíqua e que isso possibilita processos espontâneos, assistemáticos, atualizados ao sabor das circunstâncias e de curiosidades contingentes de conhecimento.

Entretanto, em meio aos professores, ainda existem muitos que demonstram resistência ao uso de tecnologia como instrumento de aprendizagem e ensino. Principalmente porque os cursos para qualificação dos docentes ainda acontecem de maneira tímida, insuficiente. Se o professor não tem segurança em utilizar os dispositivos, aplicativos, sites, ele pode criar uma certa resistência inicial. Aqui no estado da Bahia foi oferecido pela Secretaria da Educação do Estado, SEC, o curso “ Aperfeiçoamento em Tecnologias Educacionais". Todos os professores e coordenadores da rede estadual em exercício puderam participar. O curso teve duração de 180 h e foi ministrado na modalidade Educação a Distância, pela Universidade do Estado da Bahia - UNEB. Mesmo com a oferta do curso, percebemos que ainda há uma resistência muito grande por parte dos professores. Nas escolas, o celular ainda é visto como inimigo e não como possível aliado. Por que parecemos tão resistentes às mudanças culturais? A tecnologia digital está presente em todas as áreas da vida moderna, mas de maneira bem modesta na educação. É como se a escola estivesse parada no tempo, alheia a todas as mudanças que estão acontecendo. Precisamos, enquanto educadores, pensar maneiras de transformar nossas escolas, nossas salas de aula. Se nossos 
alunos estão "conectados," através dessa nova rede de comunicação podemos refletir de que maneiras participar desse contexto. A partir do uso da internet e dos dispositivos móveis podemos explorar as potencialidades de nossos alunos.

A aprendizagem através de seus recursos é natural e espontânea, pois podemos selecionar os materiais e escolher nossos caminhos de acordo com nossos interesses e motivação. A aprendizagem se dá através de descobertas individuais, de solução de problemas, de tentativas diversas, do fazer e refazer, de acordo com o ritmo de cada um. Mas a Web não é apenas um local para se resolver problemas. E um local para apresentar novas ideias, experimentar, criar. (Paiva, 2001, p. 97)

O modelo de educação atual pensa a de sala de aula e os alunos ali presentes como um ambiente homogêneo, composto por iguais. Utilizamos uma maneira uniforme de dar aula e de avaliar. Precisamos perceber que a utilização de dispositivos móveis, a exemplo do celular, pode oferecer aos nossos alunos possibilidades de ele mesmo gerir seu aprendizado e assim desenvolver sua autonomia, produzir e compartilhar conhecimento.

Como professores devemos estar atentos e analisar nossa prática, pois acredito que a escola atual não mais atenda de maneira satisfatória à essa geração de jovens completamente conectada, digital. Precisamos buscar alternativas de utilização da tecnologia associada ao ensino/aprendizagem. Paiva (2001, p. 93)) atenta para a necessidade de os cursos de formação de professores precisarem se adaptar às essas mudanças e oferecer em seus currículos disciplinas relacionadas ao uso da tecnologia na educação,

É desnecessário dizer que as tecnologias de informação deveriam fazer parte dos currículos de Letras, pois os professores deste século precisam estar tecnologicamente alfabetizados para que possam integrar essas novas formas de comunicação ao seu planejamento pedagógico.

Segundo a "Diretrizes de políticas da UNESCO para a aprendizagem móvel" (UNESCO Policy Guidelines for Mobile Learning - PG ML), São benefícios particulares da aprendizagem móvel: 
- Expandir o alcance e a equidade da educação;

- Facilitar a aprendizagem individualizada;

- Fornecer retorno e avaliação imediatos;

- Permitir a aprendizagem a qualquer hora, em qualquer lugar;

- Assegurar o uso produtivo do tempo em sala de aula;

- Criar novas comunidades de estudantes;

- Apoiar a aprendizagem fora da sala de aula;

- Potencializar a aprendizagem sem solução de continuidade;

- Criar uma ponte entre a aprendizagem formal e a não formal;

- Minimizar a interrupção educacional em áreas de conflito e desastre;

- Auxiliar estudantes com deficiências;

- Melhorar a comunicação e a administração;

- Melhorar a relação custo-eficiência

Fonte: UNESCO policy guidelines for mobile learning. 2014.

A UNESCO² entende a importância da interação das tecnologias associadas à educação como formas adicionais às práticas tradicionais empregadas . Durante a MLW (Mobile Learning Week) ${ }^{3}$, ela apresentou um conjunto de objetivos para políticas sobre m- learning ou mobile learning:

- Improving levels of adult and youth literacy: how mobile technologies can support literacy development and increase reading opportunities;

${ }^{2}$ A UNESCO - Organização das Nações Unidas para a Educação, a Ciência e a Cultura (UNESCO) foi criada em 16 de novembro de 1945, logo após a Segunda Guerra Mundial, com o objetivo de garantir a paz por meio da cooperação intelectual entre as nações, acompanhando o desenvolvimento mundial e auxiliando os EstadosMembros - hoje são 193 países - na busca de soluções para os problemas que desafiam nossas sociedades. É a agência das Nações Unidas que atua nas seguintes áreas de mandato: Educação, Ciências Naturais, Ciências Humanas e Sociais, Cultura e Comunicação e Informação.

${ }^{3}$ UNESCO will hold the Second UNESCO Mobile Learning Week (MLW) from 18 to 22 February 2013 at its Headquarters in Paris, France. 
- Improving the quality of education: how mobile technologies can support teachers and their professional development.

- Achieving gender parity and equality in education: how mobile technologies can support equal access to and achievement in basic education of good quality for all, in particular for women and girls. ${ }^{4}$ (UNESCO, tradução nossa).

\section{M- learning no ensino/aprendizagem de inglês}

Talvez o maior desafio para que a tecnologia faça parte da nossa prática pedagógica seja de fato convencer professores, diretores, coordenadores e pais. Todos nós precisamos estar convencidos da importância do uso da tecnologia no processo de ensino/aprendizagem. Muitos mostrarão resistência e com certeza não será uma tarefa simples. É muito mais rápido e fácil utilizar os dispositivos que nossos alunos já possuem do que aguardar que as nossas escolas sejam devidamente equipadas. Através de um smartphone, conectado a uma rede de dados, nossos alunos poderão ter acesso a uma infinidade de informações. Nessa nova configuração de sala de aula o professor não é aquele que detém o conhecimento mas aquele que facilita o aprendizado dos alunos. Por vezes, as relações poderão se inverter, já que os jovens dominam o uso dos dispositivos móveis. Uma hora são instruídos pelos professores, outra hora os instrui. Isso não deve ser visto como problema. Para que essa interação realmente aconteça, o professor precisa estar envolvido. Um novo currículo deve ser pensado, com ideias inovadoras. Não propomos que a tecnologia venha para substituir os métodos que conhecemos, mas para agregar novas metodologias, novos valores. $\mathrm{O}$ aprendizado não se dará apenas dentro do ambiente de sala de aula. É aí, fora dos muros da escola, numa espécie de aprendizagem informal, que justificamos o uso dos dispositivos móveis, uma vez que a tecnologia já está presente em nossas vidas, em todas as nossas

\footnotetext{
${ }^{4}$ 1-Melhoria dos níveis de letramento de jovens e adultos: como tecnologias móveis podem apoiar o desenvolvimento do letramento e aumentar as oportunidades de leitura; 2-Melhorar a qualidade da educação: como as tecnologias móveis podem apoiar os professores e seu desenvolvimento profissional; 3-Alcançar a paridade e igualdade de gênero na educação: como as tecnologias móveis podem apoiar a igualdade.
} 
atividades diárias. O que ainda nos falta é aliar esse conhecimento tecnológico a serviço da aprendizagem. Os dispositivos móveis, a exemplo dos smartphones já mudaram a nossa vida em vários aspectos: na comunicação, entretenimento, negócios, vida social, apenas a educação ainda resiste a todas essas mudanças. Até quando? Leffa (2009, p. 122) corrobora com o ilustrado acima e traz a seguinte reflexão:

O acesso a esses suportes linguísticos multimidiáticos, incluindo a internet, que está se popularizando cada vez mais, chegando à periferia, em que já é comum ver o aluno pobre carregando orgulhosamente um mp3 ou postando mensagens para seus amigos no Facebook. Ainda que a exclusão digital seja uma realidade, ela é certamente menor que a exclusão linguística; há muito mais gente sem acesso à uma língua estrangeira do que à internet. Usar os recursos digitais para ensinar a língua é uma maneira de diminuir a exclusão tanto de um lado como de outro. $\mathrm{O}$ acesso à uma língua estrangeira pode aumentar o acesso à rede, que, por sua vez, pode facilitar a aprendizagem da língua.

O próprio MEC, no PCN trata a questão de com um possível barateamento dos meios eletrônicos, mais escolas venham ter acesso a novas tecnologias, possibilitando o desenvolvimento de outras habilidades comunicativas. ( PCN, Língua Estrangeira, p. 21) A internet é um espaço atraente para os estudantes. É um lugar de descobertas, de novas possibilidades, de encontrar e fazer novos amigos. A maioria das pessoas hoje utiliza a comunicação em rede, professores e alunos, professores e professores, alunos e alunos. As redes sociais e os aplicativos substituíram o antigo telefone. Vídeo chamadas, áudio chamadas, mensagens de texto, chats, blogs fazem parte do nosso cotidiano.

É claro que o simples uso da tecnologia não encerra os problemas relacionados ao ensino aprendizado da língua inglesa. Precisamos ter cuidado em como utilizar os nossos gadgets porque devido ao excesso de informações disponíveis na rede os alunos podem por vezes se dispersar.

Segundo Brito e Purificação (2006), a escola tem a sua frente 3 possibilidades: “[...] repelir as tecnologias e tentar ficar fora do processo; apropriar-se da técnica e transformar 
a vida em uma corrida atrás do novo; ou apropriar-se dos processos, desenvolvendo habilidades que permitam o controle das tecnologias e seus efeitos" (Brito; Purificação, 2006, p. 25-26). Se nosso maior desafio como professores é motivar nossos alunos, tentando fazer um elo entre o que ensinamos e os interesses deles, devemos perceber o uso da internet e da tecnologia como possibilidade de dinamizar nossas aulas de inglês utilizando recursos variados e atrativos para nossos alunos. O ensino de língua inglesa já conheceu o laboratório de línguas. Depois vieram os livros com as fitas K-7, CDs, computadores, internet e os dispositivos móveis. A tecnologia sempre esteve presente em nossas vidas, um dia a novidade foi o lápis e o papel. Então precisamos mais uma vez nos readaptar a essa nova realidade. O primeiro desafio da educação é repensar nossa prática pedagógica e conhecer essas novas formas de acesso ao conhecimento, buscando maneiras de preparar nossos alunos para esse novo mundo onde impera a velocidade de informações. De acordo com Paiva (2001, p. 114),

Usar a internet no ensino de inglês é um desafio que demanda mudanças de atitude de alunos e professores. O aluno bem sucedido não é mais o que armazena informações, mas aquele que se torna um bom usuário de informação. O bom professor não é mais o que tudo sabe, mas aquele que sabe promover ambientes que promovem a autonomia do aprendiz e que o desafia a aprender com o(s) outro(s) através de oportunidades de interação e de colaboração.

O MEC, através dos PCN, reconhece que há muita dificuldade em contemplar o ensino das quatro habilidades na atual realidade das salas de aula das escolas públicas brasileiras. A ênfase maior é dada a leitura, enquanto que a prática da oralidade, escrita e o listening pouco ou nada são praticados.

Deve-se considerar também o fato de que as condições na sala de aula da maioria das escolas brasileiras (carga horária reduzida, classes superlotadas, pouco domínio das habilidades orais por parte da maioria dos professores, material didático reduzido a giz e livro didático etc.) podem inviabilizar o ensino das quatro habilidades comunicativas. Assim, o foco na leitura pode ser justificado pela função social das línguas estrangeiras no país e também pelos objetivos realizáveis 
tendo em vista as condições existentes. ( PCN, Língua Estrangeira, p. 21)

Dessa maneira, o uso dos dispositivos ao ensino de língua inglesa pode proporcionar aos nossos alunos a oportunidade de praticar as 4 habilidades, seja através de jogos, chats, redes sociais, aplicativos específicos para o aprendizado de idiomas, uma infinidade de possibilidades.

\section{Aprendizagem Ubíqua e as Práticas Pedagógicas na Cibercultura}

A nova geração de aparelhos sem fio, wireless, nos proporcionou mobilidade. Podemos usar nossos aparelhos sem a necessidade de estarmos ligados à rede de energia ou de internet. Através de uma rede de dados ou Wifi nos conectamos a internet. Mobilidade e conectividade. Estamos sempre conectados. É nesse contexto de acesso livre e ubíquo ao conhecimento que Santaella (2012) nos apresenta a noção de aprendizagem ubíqua:

Processos de aprendizagem abertos significam processos espontâneos, assistemáticos e mesmo caóticos, atualizados ao sabor das circunstâncias e de curiosidades contingentes e que são possíveis porque o acesso à informação é livre e contínuo, a qualquer hora do dia e da noite. Por meio dos dispositivos móveis, à continuidade do tempo se soma a continuidade do espaço: a informação é acessível de qualquer lugar. É para essa direção que aponta a evolução dos dispositivos móveis, atestada pelos celulares multifuncionais de última geração, a saber: tornar absolutamente ubíquos e pervasivos o acesso à informação, a comunicação e a aquisição de conhecimento (SANTAELLA, 2012, p. 3).

Castells (2003) no livro A galáxia da internet traz a seguinte observação:

(...) A internet é um meio de comunicação que permite, pela primeira vez, a comunicação de muitos com muitos, num momento escolhido, em escala global. Assim como a difusão da máquina impressora no ocidente criou o que Mcluhan chamou de a "galáxia de Gutenberg", ingressamos agora num novo mundo de comunicação: a "galáxia da internet". O uso da internet como sistema de comunicação e forma de organização explodiu nos últimos anos do segundo milênio. (...) A influência das redes baseadas na internet vai além do número de seus usuários: diz respeito também à qualidade do uso. 
Atividades econômicas, sociais, políticas e culturais essenciais por todo o planeta estão sendo estruturadas pela internet e em torno dela, como por outras redes de computadores. De fato, ser excluído dessas redes é sofrer uma das formas mais danosas de exclusão em nossa economia e em nossa cultura. (CASTELLS, 2003, p. 8)

Novos espaços são constituídos pela conectividade e ubiquidade. Por ser ubíquo, podemos associar a ideia de poder estar presentes em todos os lugares e ao mesmo tempo. A internet e as tecnologias de informação e comunicação móveis estão disponíveis em todos os lugares e a qualquer momento. Associadas à educação, as tecnologias digitais vêm provocando mudanças nos paradigmas de ensino/aprendizagem, tanto na realidade da sala de aula quanto na modalidade de ensino online, nos possibilitando interatividade.

Esse ambiente, criado a partir do uso das TICs ( tecnologias de informação e comunicação), é o Ciberespaço, meio de comunicação que surge a partir da conexão mundial de computadores, Levy (1999). Lugar onde as pessoas se comunicam, interagem. Um ambiente humano, mas criado com a ajuda dos dispositivos móveis. Diferente dos computadores desktops, os dispositivos móveis permitem aos usuários a facilidade de serem portáteis. Mobilidade associada a conectividade e ubiquidade transformando-nos numa geração online e modificando profundamente as relações pessoais, sociais, profissionais e os limites de tempo e espaço.

O ciberespaço (que também chamarei de "rede") é o novo meio de comunicação que surge da interconexão mundial dos computadores. O termo especifica não apenas a infra-estrutura material da comunicação digital, mas também o universo oceânico de informações que ela abriga, assim como os seres humanos que navegam e alimentam esse universo. Quanto ao neologismo "cibercultura", especifica aqui o conjunto de técnicas (materiais e intelectuais), de práticas, de atitudes, de modos de pensamento e de valores que se desenvolvem juntamente com o crescimento do ciberespaço. (LÉVY, 1999, p. 17) 
Para trazer esses conceitos para a realidade da educação, devemos pensar práticas pedagógicas que promovam o acesso de nossos alunos a cibercultura, onde ele possa produzir conhecimento de maneira colaborativa e principalmente se sinta incluído nessa nova comunidade mundial.

A sociedade contemporânea assiste o surgimento de novos excluídos. Uma grande parcela da população que ainda não tem acesso à internet, a computadores e aos dispositivos móveis. São os excluídos digitais. Sofrem uma pressão por não conseguirem utilizar as novas tecnologias, mesmo muitas vezes dominando o letramento impresso. Existe um grupo em situação ainda mais delicada que são àqueles que não dominam nem o letramento impresso e, por conseguinte, as tecnologias. Duplamente excluídos da sociedade contemporânea. Analfabytes, aqueles que não dominam as novas mídias, embora saibam ler e escrever. Iinfelizmente a educação tem feito muito pouco para mudar esse cenário.

Nesse caso, o uso da tecnologia para aprendizado de línguas surge das modificações decorrentes das novas formas de interação sociais, que possibilita que tanto professores quanto alunos participem ativamente do processo de ensino/aprendizagem. A teoria sóciointeracionista serve-nos de referencial, uma vez que analisa o ser humano como corpo e mente, inserido em um contexto histórico-social e cultural. Vygotsky defende a contínua interação entre as condições sociais e as bases biológicas que regem o comportamento humano.

...o ensino direto de conceitos é impossível e infrutífero. Um professor que tenta fazer isso geralmente não obtém qualquer resultado, exceto o verbalismo vazio, uma repetição de palavras pela criança, semelhante a de um papagaio, que simula um conhecimento dos conceitos correspondentes, mas que na realidade oculta um vácuo. (VYGOTSKY, 1998, p. 72).

A teoria de Vygotsky aponta para a importância da escola poder oportunizar aos alunos o desenvolvimento da sua criatividade, autonomia, transformando-o em sujeito ativo e não alguém propenso a ser apenas guiado. A educação não pode ser pensada deslocada do nosso dia a dia. Um dos grandes desafios da sociedade contemporânea, em tempos de globalização, seja capacitar os professores para educar o novo cidadão nessa nova 
ordem social e cultural, principalmente para alunos e professores que fazem parte da rede pública de ensino, onde imperam ainda altos índices de reprovação, evasão. Esse quadro nos obriga a pensar o que temos feito com nossos alunos e como podemos mudar essa realidade de maneira que possamos alcançar resultados mais satisfatórios

Com os novos aplicativos, e a ideia do mobile learning, o aluno adapta a língua a diferentes contextos, cria uma maneira pessoal de organizar seu conhecimento linguístico de maneira que consiga atingir o objetivo da comunicação. As novas tecnologias possibilitaram o surgimento de novos contextos, novos espaços e uma nova maneira de mediação do conhecimento.

A abordagem sócio interacionista privilegia o ambiente social, já que trata a linguagem como fator de interação social e esse desenvolvimento está relacionado com o ambiente no qual o falante está inserido. A sociedade contemporânea vive o apogeu da interação e das comunicações a partir do uso das tecnologias e da mobilidade. Segundo Santaella (2013), é a integração dos dispositivos móveis, na ubiquidade das redes, da informação, do conhecimento, da comunicação, das cidades e do pensamento é resultado da cultura digital na qual estamos imersos. O conhecimento da cultura digital pode proporcionar aos professores e profissionais envolvidos com a educação, uma maneira de ampliar os espaços não formais de aprendizagem. Santaella (2013) defende que a cultura digital está presente nos processos de aprendizagem aberta e ubíqua, que contemporaneamente possibilitam processos espontâneos, assistemáticos, atualizados ao sabor das circunstancias e de curiosidades contingentes de conhecimento.

Alguns aspectos sobre a aquisição de uma segunda língua podem ser analisados a partir da abordagem behaviorista, como define Paiva (2017, p. 15), a aprendizagem é um comportamento observável, adquirida de forma mecânica e automática por meio de estímulos e respostas. Os mecanismos centrais de formação de hábitos são o condicionamento e o reforço. Aprende-se então segundo a repetição de estruturas básicas da língua. Porém, há uma tendência para explicar a aprendizagem como um fator sociointeracional. Enquanto que na teoria behaviorista o foco era o professor e o ensino, agora dá-se maior importância 
as relações entre professores e alunos. A aprendizagem é percebida como um fator social, que depende de maneira direta do contexto histórico e social. Daí a importância em se criar estratégias de ensino que propiciem aos alunos um maior conhecimento acerca do mundo, de maneira que eles se transformem em cidadãos críticos e participativos e que possam contribuir de forma efetiva na organização da sociedade. Hilário Bohn (2013, p. 77), questionado sobre um método "soberano" para se ensinar e aprender inglês faz a seguinte colocação:

O papel do professor é de mediador, provedor de tarefas e criador de ambiente de trabalho em que o aluno pode se aproximar dessa maneira nova de significar, de compreensão e produção de palavras que cultivam um novo eu, expressam uma nova subjetividade, criam novos pertencimentos, sem abandonar os previamente estabelecidos.

O autor não faz referência ao uso das tecnologias aliadas ao ensino de línguas, porém no mesmo capítulo ele chama a atenção dos professores para que sejam criadas formas prazerosas de se ensinar e que o professor deve ter em mente que aprender uma língua é um processo linguístico e que, portanto, a linguagem deve ser o centro da atenção dos professores e alunos.

Para concluir, citamos um pensamento de Santaella (2010) que reforça o que tentamos expor:

A aprendizagem ubíqua é a disponível a qualquer momento, em que qualquer curiosidade pode ser saciada pelo acesso aos dispositivos móveis conectados em rede, fazendo com que essa informação se transforme em aprendizagem quando incorporada a outros usos.

A escola, professores, alunos, coordenadores, pais e todos os envolvidos no processo educacional precisam refletir seriamente sobre o uso da tecnologia no contexto educacional, porque não mais podemos fechar os olhos para a nova realidade que se desenha em nossa sociedade. As formas como as pessoas se comunicam, a própria questão de tempo e espaço tomaram uma dimensão completamente diferente. A tecnologia nos proporciona possibilidades variadas de acesso a conhecimento e informação e se soubermos 
associar isso às nossas práticas de sala aula, acredito que conseguiremos acessar de maneira mais efetiva nosso aluno. Enquanto muito professores veem a tecnologia com desconfiança, nossos alunos estão completamente imersos nela, os " digital natives " como diz Prensky. Para essa geração que nasceu em pleno boom da tecnologia, operar qualquer um desses gadgets é uma tarefa comum e fácil. Como poderemos perpetuar as nossas velhas práticas, utilizar os mesmos métodos se a tecnologia nos oferece uma gama incrível de possibilidades? Sem falar que podemos estar falando uma linguagem que nosso aluno não tem muito interesse em ouvir. A tecnologia sozinha não vai resolver os problemas que enfrentamos na educação; pensar assim seria utópico. Não adianta encher uma escola com computadores, internet rápida e assim achar que alunos e professores encontrarão uma fórmula mágica de sucesso. Primeiro, devemos pensar na qualificação do professor em operar os dispositivos, entender os programas e aplicativos disponíveis. É necessário e urgente que os cursos de formação de professores já tragam em seus currículos matérias que viabilizem essa preparação. Há muito ainda o que se fazer e a se conhecer, mas é preciso começar. No contexto contemporâneo de sociedade e cultura da mobilidade, nosso principal desafio como educadores é pensar novas práticas de ensino, uma vez que a noção de espaço de aprendizagem vai muito além do compreendido entre as paredes da escola.

\title{
THE USE OF MOBILE DEVICES IN ENGLISH LANGUAGE TEACHING / LEARNING
}

\begin{abstract}
Access to digital culture and new communication resources can provide teachers and education professionals with a way to expand non-formal learning spaces. We are the society of interaction and hypermobility, the result of digital culture and the use of technology. To bring these concepts to the reality of education, we must think of pedagogical practices that promote our students' access to cyberculture, where they can produce knowledge in a collaborative way and, above all, feel included in this new world community. As a theoretical reference, we used Kumaravadivelu (2016), Santaella (2010 and 2013), Castels (1999), Bohn (2014), Moran (2017), Leffa 2013, Prensky 2017, Paiva 2001, 2017, Xavier (2017), among others. The present work aims to discuss how teachers can take advantage of technologies to ensure English language learning, as well as the use of mobile devices in education, focusing on English language teaching / learning.
\end{abstract}

KEYWORDS: Use of Technology in Learning; Ubiquitous Learning, English Language; M-learning 


\section{REFERÊNCIAS}

BRASIL. Ministério da Educação e Cultura. PCN Lingua estrangeira: terceiro e quarto ciclo do ensino fundamental. Disponível em: $<$ http://portal.mec.gov.br/seb/arquivos/ pdf/pcn _estrangeira.pdf. Acesso em 20 de novembro de 2017.

CASTELS. M. A sociedade em rede. São Paulo: Paz e Terra, 1999. (A era da informação: economia, sociedade e cultura: v. 1).

- A galáxia da internet: reflexões sobre a internet, os negócios e a sociedade. Rio de Janeiro, Editora Paz e Terra - 2003.

BOHN, H. I. O método "soberano" para o ensino e aprendizagem de lingua inglesa. In: Lima, D. C. de (org.). Ensino e aprendizagem de língua inglesa: conversas com especialistas. p. 169178. São Paulo: Parábola Editorial, 2013.

BRITO, G.; PURIFICAÇÃO, I. Educação e novas tecnologias um repensar. 2. ed. Curitiba: IBPEX, 2006.

LEFFA, V. L. Por um ensino de idiomas mais includente no contexto social atual. In: Lima, D. C. de (org.). Ensino e aprendizagem de língua inglesa: conversas com especialistas. p. 113123. São Paulo: Parábola Editorial, 2009.

LÉVY, P. Cibercultura. São Paulo: Editora 34, 1999

MORAN, J. M. Como utilizar a internet na educação. Disponível em <www.scielo.br/pdf/ci /v26n2/v26n2-5.pdf > Acesso em 19 de novembro de 2017.

PRENSKY, M. Digital Native, Digital Immmigrants. Digital Native Immigrants. On the horizon, MCB University Press, Vol. 9, N.5, October, 2001. Disponível em: http://www.marcprensky.com. Acesso em: 15 de novembro de 2017.

PAIVA, V. L. M. O. A wmw e o ensino de Inglês. Revista Brasileira de Linguística Aplicada, v. 1, n. 1,93-116, 2001. Universidade Federal de Minas Gerais

PAIVA, V. L. M. O Uso da Tecnologia no ensino de linguas estrangeira: breve retrospectiva histórica. Disponível em <www.veramenezes.com/techist.pdf> acesso em 19 de novembro de 2017.

PAIVA, V.L.M. Aquisição de segunda língua. 1 ed. São Paulo: Parábola Editorial, 2017.

SANTAELLA, L. Comunicação ubíqua. Repercussões na cultura e na educação. São Paulo: Paulus, 2013.

SANTAELLA, L. A ecologia pluralista da comunicação: conectividade, mobilidade, ubiquidade. São Paulo: Paulus, 2010.

SANTAELLA, L. Aprendizagem ubíqua substitui a educação formal? Revista de Computação e Tecnologia da PUC-SP, v. 2, n. 1, 2010. 
UNESCO Policy Guidelines for Mobile Learning. Disponível em : http://www.unesco.org/ new/en/unesco/themes/icts/m4ed/unesco-mobile-learning-week/ Acesso em 18 nov. 2017.

XAVIER, A. C. dos S. Letramento digital e ensino. Disponível em http://www.nehte.com.br /artigos/Letramento-Digital-Xavier.pdf. Acesso em 18 nov. 2017.

WEINBERGER, D., Why Open Spectrum Matters. The end of the broadcast nation., in https://ecfsapi.fcc.gov/file/6513404739.pdf. 2017

VYGOTSKY, L. S. Pensamento e linguagem. 2. ed. São Paulo: Martins Fontes, 1998.

Recebido em: 16/07/2018. Aprovado em: 07/09/2018. 